\title{
Forensic Nursing in the Wake of COVID-19
}

\author{
Cindy Peternelj-Taylor, RN, BScN, MSc, DF-IAFN
}

$\mathrm{T}$ oday is April $1^{\text {st }}$; for days now, I have been staring at my computer screen, hoping that my editorial would somehow magically appear. The truth is, like many nurses throughout the world, I am consumed with the devastation of the coronavirus pandemic. Every morning, I wake up hoping I have simply had a bad dream, only to face the harsh reality of the growing numbers of COVID-19 cases that have mushroomed overnight, coupled with the painful news of increasing fatalities. Our lives have forever changed. It is hard to believe it was only on March 11, 2020, that the World Health Organization declared the coronavirus a pandemic.

Every day, people throughout the world are struggling to adapt to a new normal, in an attempt to cope with selfisolation, travel restrictions, shelter in place orders, and more. Such actions were implemented in an attempt to "flatten the curve," or as Dr. Theresa Tam, Chief Public Health Officer of Canada, said more recently, we need to go beyond flattening the curve-we need to "plank" it. And while we personally long for a sense of familiarity and stability in our lives, we know intellectually, if not emotionally, that the decisions that we embrace as we adhere to the constantly changing restrictions and recommendations will indeed make a difference.

As forensic nurses, we know that the patients and clients whom we care for under "normal" circumstances are at an increased risk because of the measures that have been implemented to prevent the spread of this deadly virus. We understand intuitively that too much time together, and increased social isolation, places many vulnerable members of our communities at an increased risk for sexual abuse, intimate partner violence, elder abuse, and child abuse. We also know that criminal justice involved persons, refugees, and homeless persons are also at an increased risk of contracting the virus, given the overcrowding commonly

\footnotetext{
Author Affiliation: College of Nursing, University of Saskatchewan.

The author declares no conflict of interest.

Correspondence: Cindy Peternelj-Taylor, RN, BScN, MSc, DF-IAFN, College of Nursing, University of Saskatchewan, 4214-104 Clinic Place, Saskatoon, SK, Canada S7N $2 Z 4$. E-mail: cindy.peternelj-taylor@usask.ca.

Copyright (C) 2020 International Association of Forensic Nurses DOI: 10.1097/JFN.0000000000000292
}

found in jails, prisons, processing centers, shelters, and other forms of temporary housing, where social distancing (among other precautions) is impossible to adhere to. Regardless of the area of forensic nursing one aligns with, forensic nurses are among the unsung heroes, assuming leadership in caring for the most vulnerable members of society.

The Journal of Forensic Nursing is the official journal of the International Association of Forensic Nurses (IAFN); as an Editorial Board, we applaud the leadership shown by the association during this troubling time. Tune into the informative 20-minute video COVID and Patient Care produced by the IAFN (2020) Home Office Staff, as they discuss the importance of forensic nurses caring for sexual assault patients and victims of violence. Designed to reach both forensic nurses and persons who have experienced violence, the staff members emphasize the significance of a medical forensic examination as opposed to a victim-administered evidence kit (Pierce-Weeks, 2019). Furthermore, the presenters stress the necessity of reassuring the public that it is safe to seek health care, as well as the importance of taking care of patients' holistic healthcare needs, and of connecting them with local services and resources to assist with shortand long-term issues that may emerge. The COVID-19 crisis has forced forensic nurses to think and practice "outside of the box" - a familiar role for forensic nurses. This may include moving sexual assault services outside emergency departments and hospitals and connecting patients with advocates by whatever means they have at their disposal, whether it be through telehealth connections or by telephone. The ultimate goal is the safety of patients and staff. Clearly, a "one size fits all" approach would be impossible to achieve given the ever-changing diversity of restrictions and recommendations emerging across jurisdictions. To that end, the IAFN has provided a list of vetted resources to keep forensic nurses informed during this pandemic. For further information, please see forensicnurses.org/covid. Finally, the importance of consulting and collaborating with local public health officials and administrators is essential across states, provinces, and countries.

The Journal of Forensic Nursing is open for business. We continue to process manuscripts as usual. However, in doing so, we recognize that the professional and personal lives of our contributors and reviewers have been upended. We also recognize that, during the coronavirus 


\section{Editorial}

crisis, writing may not be high on anyone's agenda, and reviewers may be consumed with other pressing issues as they attempt to make sense of their ever-changing reality. During this unprecedented time in the history of the journal, we will continue to do our best to meet the needs of authors, reviewers, and readers, and we thank you for your continued support. Moreover, we are very interested in learning more about forensic nurses' responses to COVID-19, how you are coping, challenges your patients and clients are experiencing, and your messages of optimism and hope. We want to hear your stories, so we may share your contributions with our readership. Thank you in advance for your consideration.
We are thinking of each of you during this challenging time; we hope you are well, and we hope you are safe. Remember, self-care is not selfish care-now more than ever, this should be our mantra. Please take some time, even if only a little, to care for yourself. We are all in this together, and together, we will get through this.

\section{References}

International Association of Forensic Nurses. (2020). COVID and patient care [Video]. https://wnw.youtube.com/watch?v=qemqa3T9908

Pierce-Weeks, J. (2019). Forensic nursing response to victimadministered evidesnce kits. Journal of Forensic Nursing, 15(4), E1. https://doi:10.1097/JFN.0000000000000266. 